\title{
A Survey Of Student Perspectives Toward Faculty Evaluations
}

Tom Slocombe, Emporia State University, USA

Donald Miller, Emporia State University, USA

Nancy Hite, Emporia State University, USA

\begin{abstract}
This study was designed to help faculty and administrators weigh the value of using student ratings of professors' teaching effectiveness and to determine factors that may affect those ratings. For this study, conducted at a Midwestern AACSB accredited School of Business, 163 students (23\% of the business majors) were surveyed to determine their perceptions concerning student ratings of faculty. Although 100\% of the students surveyed believed they were honest in their evaluations, only $33 \%$ of them believed other students were honest. International students tended to give higher evaluations in math-related classes than U.S. students. Students tended to give higher evaluations to professors who used humor and to professors they liked. They did not give higher evaluations to male professors or ones under 55 years of age. The difficulty of the class did not impact students' ratings of faculty.
\end{abstract}

Keywords: student ratings; educator effectiveness; student perceptions

\section{BACKGROUND PERSPECTIVES}

$\mathrm{n}$ the late 1920s, Douglass (1928) noted the prevalence of differing opinions associated with student ratings of instruction. Also, he recognized the ease of collecting these opinions and potential relevance for examining them as a source of information. Yet, the complexities related to use of student evaluations continue to prevail in the $21^{\text {st }}$ Century. With demands for more accountability in an environment increasingly characterized by a need to produce greater results with fewer resources, the interest in evaluation of teaching effectiveness may be expected to continue. Seemingly, various stakeholder groups, including educational administrators, students, and faculty, expect their viewpoints to be recognized.

Over the years, the focus of student rating initiatives has shifted. According to Solis (2003), initial interest originated in the 1920s as a way for students to assist each other in selecting courses. During the 1960s, more faculty members were required to be evaluated by students, and student ratings emerged as a topic of considerable research in the 1970s. Algozzine, Beattie, and Bray (2004) observed an emphasis on continued clarification as an integral component of research from the 1980s to mid-1990s. More recently, student evaluations focused on applications of technology and a variety of alternative uses, including consideration of student and professor expectancies.

McKeachie and Kaplan (n.d.) observed the potential for student rating procedures to provide valid and worthwhile information concerning instructional effectiveness. Yet, different research endeavors revealed various outcomes. Yunker and Yunker (2003) studied ratings of students enrolled in Intermediate Accounting I, after taking Introductory Accounting I from a more highly rated professor, and found they performed less well than students who took the introductory course with a less highly rated professor. Read, Rama, and Raghunandan (2001) surveyed accounting administrators at AACSB institutions and noted that student ratings indicated only limited information about instructional performance. Pinto and Mansfield (2010) and Carrell and West (2010) reached somewhat similar conclusions about the use of student ratings for administrative purposes. Interestingly, Chen and Hoshower (1998) conducted a study involving students who took various accounting courses and a personal income tax class. From the perspective of students, they found that the least important use of student ratings involved 
promotion, tenure, and financial decisions for faculty. Also, student motivation to participate in the evaluation process was significantly related to a belief that they could provide useful feedback.

At times, a concern has arisen over whether professors can positively influence student ratings by giving high grades. Using a sample of 607 economics classes, McPherson (2006) observed that students who expected high grades gave significantly better student ratings in both fundamental and higher level courses. In addition, higher scores were attained in smaller classes. Ahmadi, Helms, and Raizadeh (2001) reported results of a study involving business students at the University of Tennessee-Chattanooga and found that courses without homework, taught by professors who were thought to give easier tests, did not receive higher evaluations. A study by Kozub (2010) included 436 students enrolled at the University of Wisconsin-Milwaukee and revealed a significant correlation between anticipated course grades and overall ratings of teaching effectiveness. Surprisingly, a course taken as an elective was considered to be significantly more worthwhile than if taken to meet general education or major/minor requirements.

Research on student perspectives has considered a variety of variables, including age, gender, and course related activities. In a study conducted by Arbuckle and Williams (2003), 352 male and female students viewed a series of gender and age neutral "stick figure" slides and heard a voice neutral lecture. Based on voice alone and no discernible image of males or females, the "young male" professors received higher evaluations on manner of speaking and useful tone of voice than did "young female" or "old male/female" professors. Gaultney and Cann (2001) studied preferences of students enrolled in sections of an introductory psychology course and found that females wanted a greater number of opportunities to be evaluated but with less emphasis placed upon each of the evaluations. Also, they learned that students preferred interesting/fun assignments and believed that failure of instructors to recognize their effort contributed to students' receiving lower grades than might be expected.

Among other studies, Bastow (2000) surveyed students to determine potential existence of gender perceptions in descriptions of their best and worst professors. Female professors were selected as the best professors to a greater extent by women and to a lesser extent than anticipated by men. As related to the worst professor, no gender differences were apparent.

Professors' attire, attitudes, and race have also been analyzed. Appropriate attire impacts numerous organizational dynamics, including personnel considerations (Rafaeli \& Pratt, 1993). In a survey involving both business and non-business students, professional classroom attire positively influenced student opinions about the education they received and also their views toward their university (Carr, Davies, and Lavin, 2010). This research revealed no significant differences between perspectives of business and those of non-business students. A study of student attitudes (Kim, Damewood, \& Hodge, 2000) of undergraduate students at a Midwestern university concluded that professors who showed attitudes that were perceived as positive received higher student ratings. Minority professors appear to receive lower evaluations than other professors. One study comparing evaluations of instructors teaching online classes vs. face-to-face classes found minority instructors received significantly lower average student evaluations of teaching effectiveness in face-to-face classes than online classes (Carle, 2008). Additionally, Merritt (2008) believes a professor's race and other factors that have little relation to learning have an impact on student rating results.

Differing opinions prevail concerning the integrity of student responses on ratings of instructional performance of faculty. Detchen (1940) indicated a view that, when provided with chances to express their opinions, students will sincerely give them. More recently, new technology has provided opportunities for students to record opinions about professors through websites. By surveying students who utilized such a website, Brown, Baillie, and Fraser (2009) noted that results from such a site (RateMyProfessors.com) correlated moderately or higher with standard evaluations of teaching. In an interesting study, McNatt (2010) sampled first year MBA students who were enrolled for full-time study; he found that negative information, which was given to students about a professor, continued to persist even though actual teaching performance was positive. In the Ahmadi, Helms, and Raiszadeh study (2001), the researchers observed that a majority of students indicated a sincere perspective in their approach to student ratings.

In summary, the literature reveals that a wide variety of studies have been conducted related to the rating of faculty effectiveness. 


\section{PURPOSE OF THE STUDY}

Higher education is living through an era of assessment and accountability with greater emphasis being placed on gathering and evaluating data of all types. Today, many universities require all faculty members be rated by students on teaching effectiveness. Assessment results are often used to determine faculty members' retention, merit pay, and promotion. Because these student assessments of teaching effectiveness are used to make crucial decisions affecting individual professional lives, professors often question whether students take the faculty evaluation process as seriously as they should and as seriously as administrators often do. Additionally, professors often question the influence extraneous factors and students' personal biases may have on their perceptions of instructor effectiveness--biases professors cannot control.

The overall purpose of this study is to help faculty members and administrators weigh the value of using student ratings of professors' teaching effectiveness, given the various factors that affect those evaluations. Specifically, this research study is designed to determine the following: (1) how honest and serious students are when they fill out faculty teaching effectiveness rating forms; (2) the factors that have the most influence on student ratings of professors' teaching effectiveness: (3) the influence of various student demographic factors on teaching evaluations including age, citizenship, overall grade point average, and hours worked on student ratings of professors: and (4) student perceptions of how results from the student ratings are used by professors and administrators.

\section{METHOD}

This study was conducted at a Midwestern AACSB accredited School of Business that requires student evaluations of professors teaching effectiveness using a norm-based evaluation tool. Data were collected by surveying a population of junior and senior School of Business students who had experience filling out faculty evaluation forms and who were enrolled in Principles of Management and Business Policy courses. Those courses were selected to ensure a cross-section of students from all six majors within the school since they are required of all business majors.

A literature review (Sprinkle, 2009; Sprinkle, 2008; Brown, 2008; Weinstein, 2010; \& Carr, 2009) revealed no teaching effectiveness studies that provided an appropriate survey form for use in this study. Therefore, the authors created a survey form consisting of 21 items and eight demographic questions. Student responses to each statement were gathered using a Likert-type scale with $1=$ strongly disagree, $2=$ disagree, $3=$ agree, and $4=$ strongly agree. No neutral response was allowed as it was believed that all participants would be able to agree or disagree with the various statements on the questionnaire.

The survey was pilot tested with students enrolled in two business communications classes at this university to solicit their recommendations related to readability, content, and length of the survey and to determine face validity. Based on the pilot test, minor revisions were made to the survey instructions as well as some survey items. The University's Human Subjects Review Board approved the survey instrument prior to administration. The survey was distributed to 163 students enrolled in either Principles of Management or Business Policy courses to determine their opinions concerning faculty teaching evaluations filled out by students. The 163 students surveyed represent approximately $23 \%$ of the 718 students majoring in business. Verbal and written directions given to students by the survey authors indicated participation was voluntary and their responses would be anonymous.

Statistical treatment of the data included the use of the Statistical Package for Social Sciences (SPSS). Descriptive statistics were used to organize, summarize, and describe the collected data. The $t$-test was used to determine whether there were statistically significant differences in responses based on various demographic classifications. The Pearson product moment correlation coefficient with an alpha level of $p>.05$ was used to test the significance of correlations.

\section{RESULTS}

The 21-item survey was distributed to 163 students in the School of Business; $51 \%$ were males and $49 \%$ were females with $84 \%$ being native-born U.S. citizens and 16\% international students. Seventy-six percent of the 
participants were 24 years of age or younger and $24 \%$ were 25 years of age or older. Nearly all student participants were juniors or seniors (94.5\%), and all of them had a minimum GPA of 2.0 or higher. Forty-one students did not work, but 122 students did work with hours worked ranging from three hours per week to 75 hours per week. Semester hours taken during the current semester ranged from 3 to 24 credits. Twenty students had taken online courses.

Table 1 provides descriptive statistics (mean and standard deviation) for all 21 items in the survey. The three survey items that students agreed with most strongly indicate the students believed (1) they learned more if they liked the professor, (2) they were honest when filling out teacher evaluations, and (3) they took the evaluations seriously. On the 4-point scale, the means for those items fell about half-way between agree and strongly agree. Students expressed strongest disagreement with the items that asked if they gave higher evaluations to male professors and those under 55 years of age.

Student honesty was dealt with in two different survey items. As a double check on the honesty of students when filling out faculty evaluations, one item asked about their own honesty when completing teacher evaluations $(M=3.45, S D=.499)$ and another asked about whether they believed other students were honest when filling them out $(M=2.68, S D=.659)$. While $100 \%$ of the students agreed or strongly agreed that their teaching evaluations were honest, about $33 \%$ of the students did not believe other students were honest when filling out the teaching evaluations. In fact, students' perceptions of their own honesty were not significantly correlated with students' perceptions of the honesty of other students, $r=.109, p=.169, N=163$.

Two survey items dealt with the effect of students liking the professor. Ninety-five percent of the students indicated they learned more if they liked the professor and $64 \%$ indicated that liking the professor was at least as important as the amount of knowledge acquired.

A mean score of 2.23 and standard deviation of .860 for the item dealing with giving higher evaluations to professors who dress professionally indicates no strong influence of professional attire on faculty ratings.

Table 1: Descriptive Statistics For Student Perceptions Of Factors Affecting Teacher Evaluations (n=163)

\begin{tabular}{|c|c|c|c|}
\hline Factors & $N$ & $M$ & $S D$ \\
\hline I learn more if I like the professor. & 163 & 3.50 & .592 \\
\hline I believe my teaching evaluations are honest. & 163 & 3.45 & .499 \\
\hline I take the evaluations seriously. & 163 & 3.40 & .594 \\
\hline I believe professors use evaluations to improve courses. & 163 & 2.91 & .646 \\
\hline I give higher evaluations to professors who use humor. & 162 & 2.81 & .750 \\
\hline How well I like the professor is as important as the amount of knowledge gained. & 162 & 2.71 & .770 \\
\hline I believe other students are honest in filling out teaching evaluations. & 160 & 2.68 & .659 \\
\hline I believe evaluations affect faculty salaries. & 159 & 2.31 & .737 \\
\hline I give higher evaluations to professors who seem to give many A's in classes. & 163 & 2.29 & .860 \\
\hline I give lower evaluations in difficult classes. & 163 & 2.26 & .750 \\
\hline I give higher evaluations in classes in which I expect a good grade. & 163 & 2.24 & .752 \\
\hline I give higher evaluations to professors who dress professionally. & 162 & 2.23 & .860 \\
\hline I give lower evaluations in classes requiring a lot of writing. & 163 & 2.17 & .631 \\
\hline I give lower evaluations in classes with unusually large numbers of students. & 162 & 2.08 & .659 \\
\hline I give higher evaluations in classes involving math, computations, and formulas. & 163 & 2.07 & .614 \\
\hline I give lower evaluations in classes with more homework. & 163 & 2.05 & .710 \\
\hline I give higher evaluations in online classes. & 124 & 1.93 & .700 \\
\hline I give lower evaluations in classes with more than 4 exams. & 163 & 1.93 & .668 \\
\hline I give lower evaluations in classes requiring a team project. & 163 & 1.92 & .608 \\
\hline I give higher evaluations to professors under 55 years old. & 162 & 1.62 & .590 \\
\hline I give higher evaluations to male professors. & 163 & 1.49 & .548 \\
\hline
\end{tabular}

Note: Scale: 1=Strongly disagree, $2=$ Disagree, $3=$ Agree, and 4=Strongly agree . 
Over $70 \%$ of the students surveyed either disagreed or strongly disagreed with the following items: (1) I give lower evaluations in classes that require substantial amounts of writing, (2) I do not give lower evaluations in classes that require more homework, and (3) I do not give lower evaluations in classes that require team projects. About $55 \%$ of the students in this study indicated they did not give higher evaluations to faculty who they believed gave lots of A's in their classes and about $62 \%$ did not give lower evaluations in difficult classes.

Relationships among the survey items and various demographic factors were also analyzed. U.S. students $(M=2.00, N=134)$ gave lower faculty evaluations in courses involving mathematics than international students $(M$ $=2.44, N=25), p=.004, t=3.150)$. Students who worked a higher number of hours per week were not more likely than students who worked fewer hours per week to give lower evaluations in difficult courses $(r=.185, p=.018, N$ $=163$.)

In several instances, no significant relationship was found between survey items and demographic factors. Students who had completed more online courses did not indicate a tendency to give higher evaluations in online courses $(r=.146, p=.108, N=122)$. Although English was a second language for many international students, there was no significant difference between international $(M=2.36, N=25)$ and U.S. students' $(M=2.13, N=134)$ ratings of faculty who took classes requiring a lot of writing, $p=.092, t=1.695$. Students' GPA had virtually no relationship to any tendency to give higher evaluations to professors who gave many A's in their classes, $r=.025, p$ $=.751$.

Students of all ages disagreed with the statement that they would give higher evaluations to professors under 55 years of age. Only seven students indicated they would give higher evaluations to younger professors and those seven students were evenly distributed across the age categories.

\section{CONCLUSIONS AND DISCUSSION}

The honesty of students when completing faculty evaluation forms has been an ongoing concern as well as how serious they really take the faculty evaluation process. Results of this study showed that $100 \%$ of the students believed they were honest in their ratings of professors; however, approximately $33 \%$ of them did not believe other students were honest in their ratings. This conundrum brings into question the value and weight that professors and especially administrators should give to student ratings since a substantial percentage of students believe other students are not giving accurate ratings to their professors. On the other hand, students indicated they take faculty evaluations seriously and believe professors use evaluations to improve courses.

Some faculty may believe that they get lower student evaluations in classes that involve math, writing, teamwork projects, or lots of homework. This study found that was only true for math-related courses with U.S. students and not international students. Professors who teach math-related courses and receive low student ratings from U.S. students may have a legitimate argument to make with administrators when their ratings are compared to professors who do not teach math-related courses.

This study found no relationship existed between the age of student respondents and the ratings they gave to professors based on their age. However, this was in contrast to results of a study by Sprinkle (2008) indicating that as student age increased, so did their rating of older professors' effectiveness.

Students indicated they give higher evaluations to professors who use humor in their classes, and they believed they learned more in classes where they liked the professor. In fact, students indicated liking the professor was as important as acquiring knowledge. At a time when business schools appear to be placing more emphasis on summative assessment of students' knowledge through the use of the ETS Major Field Test in Business, it is interesting that student ratings of faculty members may be more influenced by how much they like a professor than how much they have learned in the course. This finding provides little guidance to professors who want to pursue this nebulous trait of being liked by students. Additionally, knowing that students give higher ratings to humorous professors may not help professors improve their ratings either because being humorous is not an easily acquired trait. 
Because of the factors described above that significantly affect student ratings of faculty, some of which are outside the control of professors, administrators' should make judicious use of student ratings of professors when making crucial salary and/or employment decisions such as promotion and tenure.

\section{AUTHOR INFORMATION}

Dr. Tom Slocombe is a professor of management at Emporia State University.

Dr. Donald Miller is a professor of management at Emporia State University.

Dr. Nancy Hite is a professor in business education at Emporia State University.

\section{REFERENCES}

1. Ahmadi, M., Helms, M., \& Raiszadeh, F. (2001). Business students' perceptions of faculty evaluations. The International Journal of Educational Management, 15 (1), 12-22.

2. Aleamoni, L. (1999). Student rating myths versus research facts from 1924-1998. Journal of Personnel Evaluation in Education, 13(2), 153-166.

3. Algozzine, B., Beattie, J., \& Bray. M. (2004). Student evaluation of college teaching. College Teaching, 52 (4), 134-141.

4. Arbuckle, J., \& Williams, B. (2003). Student's perceptions of expressiveness: Age and gender effects on teacher evaluations. Sex Roles, 49 (9/10), 507-516.

5. Bastow, S. (2000). Best and worst professors: Gender patterns in students' choices. Sex Roles, 43 (5/6), 407-417.

6. Brown, M., Baillie, M., \& Fraser, S. (2009). Rating Ratemyprofessors.com: A comparison of online and official student evaluations of teaching. College Teaching, 57 (2), 89-92.

7. Brown, M. (2008). Student perceptions of teaching evaluations. Journal of Instructional Psychology, 35(2), 177-181.

8. Carle, A. (2009). Evaluating college students' evaluations of a professor's teaching effectiveness across time and instruction mode (online vs. face-to-face) using a multi-level growth modeling approach. Computers \& Education, 53(2), 429-435.

9. Carr, D., Davies, T., \& Lavin, A. (2010). The impact of instructor attire on college student satisfaction. College Student Journal, 44 (1), 101-111.

10. Carr, D., Davies, T., \& Lavin, A. (2009). The effect of business faculty attire on student perceptions of the quality of instruction and program quality. College Student Journal, 43(1), 45-55.

11. Carrell, S., \& West, J. (2010). Does professor quality matter? Evidence from random assignment of students to professors. Journal of Political Economy, 118 (3), 409-432.

12. Chen, Y., \& Hoshower, L. (1998). Assessing student motivation to participate in teaching evaluations: An application of expectancy theory. Issues in Accounting Education, 13 (3), 531-549.

13. Detchen, L. (1940). Shall the student rate the professor? The Journal of Higher Education, 11 (3), 146-154.

14. Douglass, H. (1928). Rating the teaching effectiveness of college instructors. School and Society, 28, 192-197.

15. Gaultney, J., \& Cann, A. (2001). Grade expectations. Teaching of Psychology, 28 (2), 84-87.

16. Kim, C., Damewood, E., \& Hodge, N. (2000). Professor attitude: Its effect on teaching evaluations. Journal of Management Education, 24 (4), 458-473.

17. Kozub, R. (2010). Relationship of course, instructor, and student characteristics to dimensions of student ratings of teaching effectiveness in business schools. American Journal of Business Education, 3 (1), $33-40$.

18. McKeachie, W., \& Kaplan, M. (n.d.). Persistent problems in evaluating college teaching. Retrieved July 10, 2010, from http://cedar.olemiss.edu/depts/vc_academic_affairs/problems.html

19. McNatt, D. (2010). Negative reputation and biased student evaluations of teaching: Longitudinal results from a naturally occurring experiment. Academy of Management Learning \& Education, 9 (2), 225-242. 
20. McPherson, M. (2006). Determinants of how students evaluate teachers. Journal of Economic Education, 37 (1), 3-20.

21. Merritt, D. (2008). Bias, the brain, and student evaluations of teaching. St. John's Law Review, 82 (1), 235-270.

22. Pinto, M., \& Mansfield, P. (2010). Thought processes college students use when evaluating faculty: A qualitative study. American Journal of Business Education, 3 (3), 55-60.

23. Rafaeli, A., \& Pratt, M. (1993). Tailored meanings: On the meaning and impact of organizational dress. Academy of Management. The Academy of Management Review. 18 (1), 32-55.

24. Read, W., Rama, D., \& Raghunandan, K. (2001, March/April). The relationship between student evaluations of teaching and faculty evaluations. Journal of Education for Business, 76 (4), 189-192.

25. Solis, M. (2003, November). Evaluation vs. assessment: The students perspective on the student evaluation process. Culture Society \& Praxis, 2 (1), 7-22.

26. Sprinkle, J. (2008). Student perceptions of effectiveness: An examination of the influence of student biases. College Student Journal, 42(2), 276-293.

27. Sprinkle, J. (2009). Student perceptions of educator effectiveness: A follow-up study. College Student Journal, 43(4), 1341-58.

28. Weinstein, L. (2010). What motivates college students to learn. College Student Journal, 44(2), 272-274.

29. Yunker, P., \& Yunker J. (2003, August). Are student evaluations of teaching valid? Evidence from an analytical business core course. Journal of Education for Business, 78 (6), 313-317. 
NOTES 